\title{
Myelomatous Pleural Effusion as a Presenting Symptom: A Case Report
}

\author{
Alejandro Rodelo ${ }^{1}$, Jitesh Joshi ${ }^{1}$ \\ 1. Medical Oncology / Hematology, Houston Methodist Hospital, Houston, USA
}

Corresponding author: Jitesh Joshi, jjoshi@houstonmethodist.org

\begin{abstract}
Myelomatous pleural effusion (MPE) is a rare complication in patients suffering from multiple myeloma (MM). Dyspnea is the predominant symptom in the clinical presentation. Poor prognosis and aggressive MM behavior have been linked to this condition. We describe a case of MPE in an undiagnosed MM patient who presented with respiratory discomfort and general malaise.
\end{abstract}

Categories: Pathology, Oncology

Keywords: multiple myeloma, pleural effusion, hematology

\section{Introduction}

Multiple myeloma (MM) is a malignant plasma cell disorder accounting for $10 \%$ of all hematologic malignancies [1]. Hallmarks for this disease can be summarized by the CRAB mnemonic: hypercalcemia, renal failure, anemia, and lytic bone lesions predominantly of the skull [2]. MM is theorized to evolve from an asymptomatic premalignant stage known as monoclonal gammopathy of undetermined significance (MGUS) with a $1 \%$ yearly risk of progression [1]. We report a case of a patient presenting with MM and pleural effusion as her initial symptom.

\section{Case Presentation}

A 74-year-old female presented to our hospital with complaints of involuntary weight loss, night sweats, and a one-week history of worsening dyspnea and palpitations. Her previous medical history included atrial fibrillation and mastectomy due to breast cancer; the rest of her history was otherwise unremarkable. Upon admission, she was found to be dyspneic, tachycardic, and in atrial fibrillation with a rapid ventricular response. A chest X-ray (Figure 1) followed by a computed tomography (CT) scan (Figure 2) were performed; the findings were a large pericardial effusion and moderate bilateral basal pleural effusions. Lab testing revealed anemia. Serum creatinine and calcium were within normal limits (Table 1).

\footnotetext{
Received 07/01/2019

Review began 07/04/2019

Review ended 07/13/2019

Published 07/16/2019

๑) Copyright 2019

Rodelo et al. This is an open access

article distributed under the terms of the Creative Commons Attribution License CC-BY 3.0., which permits unrestricted use, distribution, and reproduction in any medium, provided the original author and source are credited.
} 


\section{Cureus}

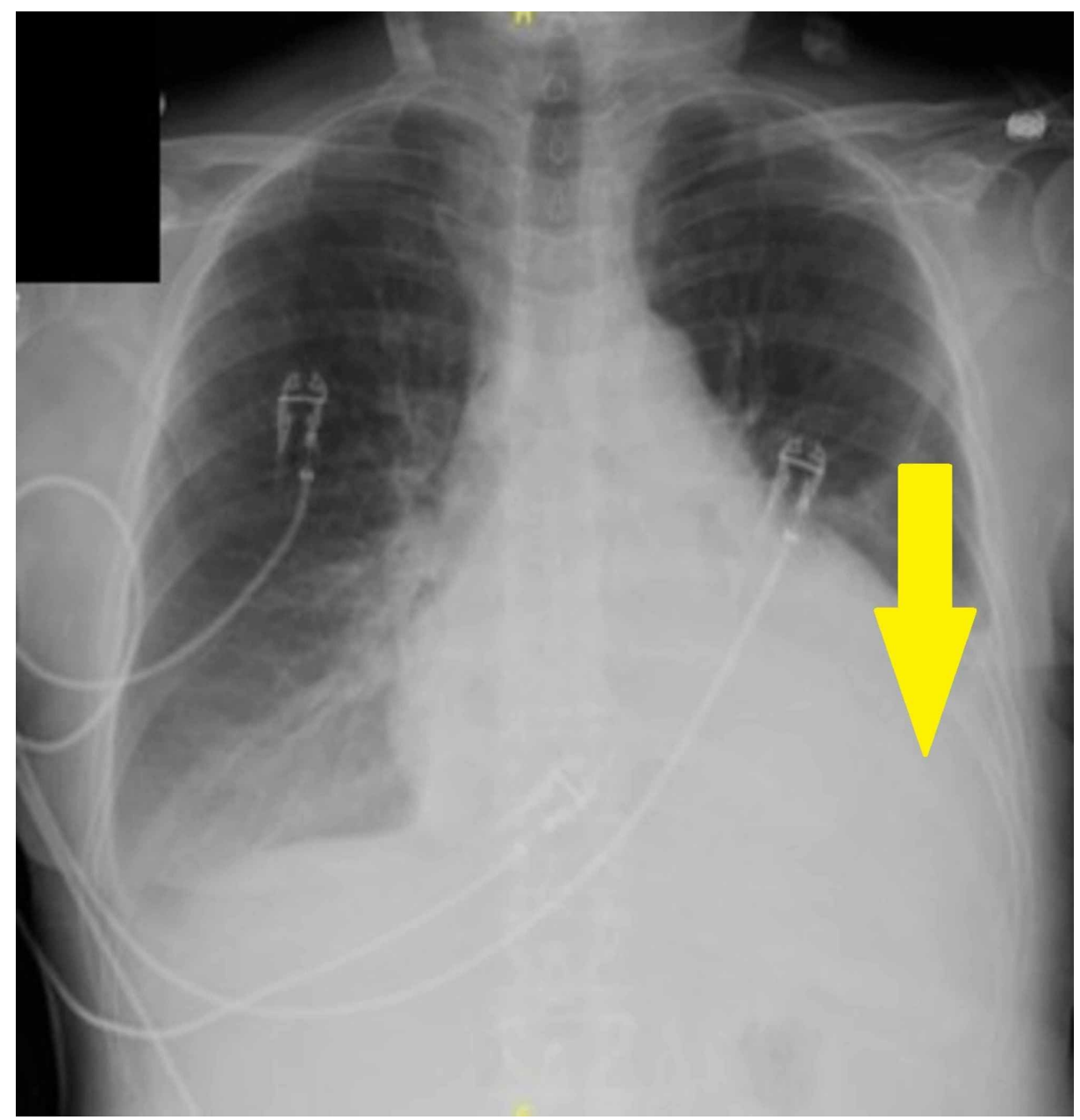

FIGURE 1: Chest Radiograph - Pleural Effusion 


\section{Cureus}

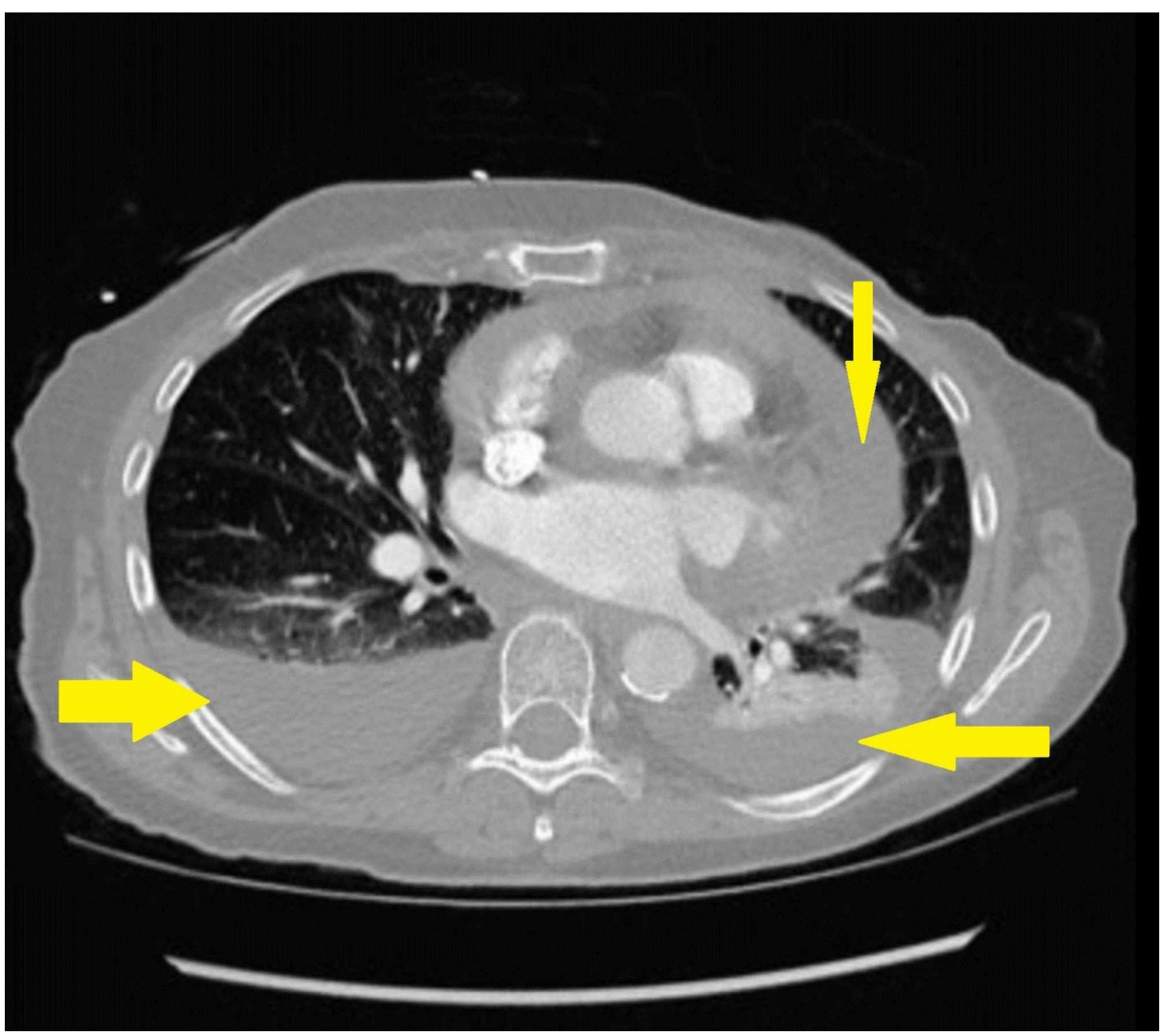

FIGURE 2: CT Chest Scan - Bilateral Pleural and Pericardial Effusions

CT: Computed Tomography

\begin{tabular}{|c|c|c|c|}
\hline & Reference Range & Day 1 & Day 45 \\
\hline HGB & $12.0-16.0 \mathrm{~g} / \mathrm{dL}$ & 7.0 (LL) & 10.2 \\
\hline HCT & $37.0-47.0 \%$ & 23.4 (L) & 33.3 \\
\hline Platelet Count & $150-400 \mathrm{k} / \mathrm{uL}$ & 186 & 186 \\
\hline $\lg A$ & $70-400 \mathrm{mg} / \mathrm{dL}$ & $68(L)$ & $<50$ (L) \\
\hline $\lg \mathrm{g}$ & $700-1,600 \mathrm{mg} / \mathrm{dL}$ & 2,334 (H) & 1,075 \\
\hline $\lg M$ & $33-255 \mathrm{mg} / \mathrm{dL}$ & $<25$ (L) & $<25$ (L) \\
\hline Kappa Light Chain & $3.30-19.40 \mathrm{mg} / \mathrm{L}$ & $705.00(\mathrm{H})$ & 11.24 \\
\hline Lambda Light Chain & $5.70-26.30 \mathrm{mg} / \mathrm{L}$ & $<2.10$ (L) & $<2.10$ (L) \\
\hline M Spike & & $1.1 \mathrm{mg} / \mathrm{dL}$ & $0.5 \mathrm{mg} / \mathrm{dL}$ \\
\hline
\end{tabular}

\section{TABLE 1: Laboratory Values}

HGB: Hemoglobin, HCT: Hematocrit, Ig: Immunoglobulin, M-spike: Monoclonal Spike

The patient was admitted to the intensive care unit (ICU), where she was started on amiodarone drip and diuresis. She received three units of pRBC for symptomatic anemia. Pericardial effusion was drained,

revealing 8 cc of dark fluid with no viable cells. She was investigated by hematology for a possible plasma cell dyscrasia. The free light chain ratio and immunoglobulin $\mathrm{G}(\mathrm{IgG})$ were significantly increased. A bone marrow biopsy was performed, which showed extensive plasma cell infiltration (80\% involvement).

Cytogenetics and fluorescence in situ hybridization (FISH) studies demonstrated a gain of chromosome 9 and 13q/14 (RB1) deletion (Figures 3-4). IgG kappa MM was diagnosed. No bone lesions were found on the 


\section{Cureus}

staging magnetic resonance imaging (MRI) bone survey or positron emission tomography (PET) scan.

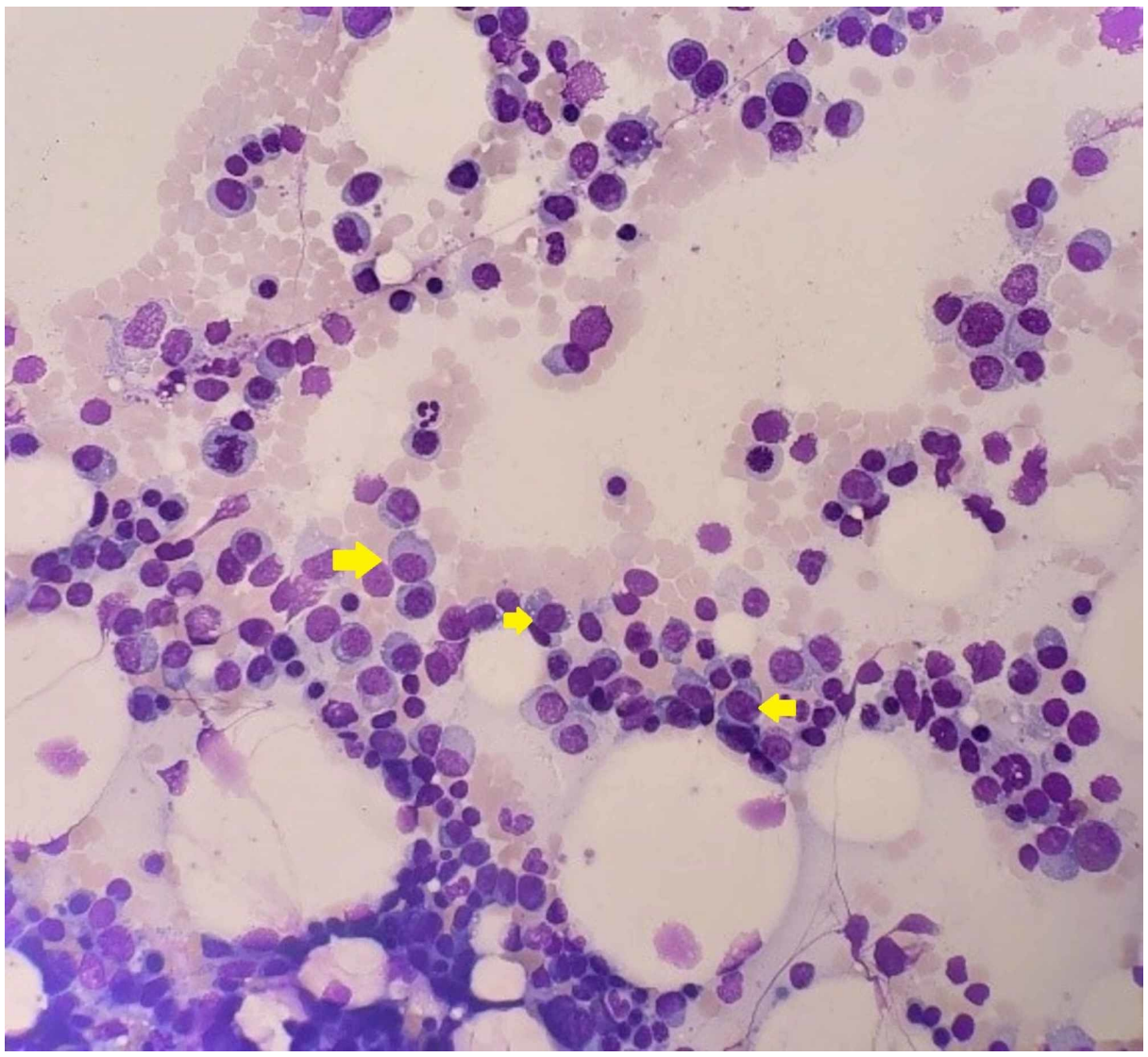

FIGURE 3: Hematoxylin and Eosin Stain of Bone Marrow Aspirate

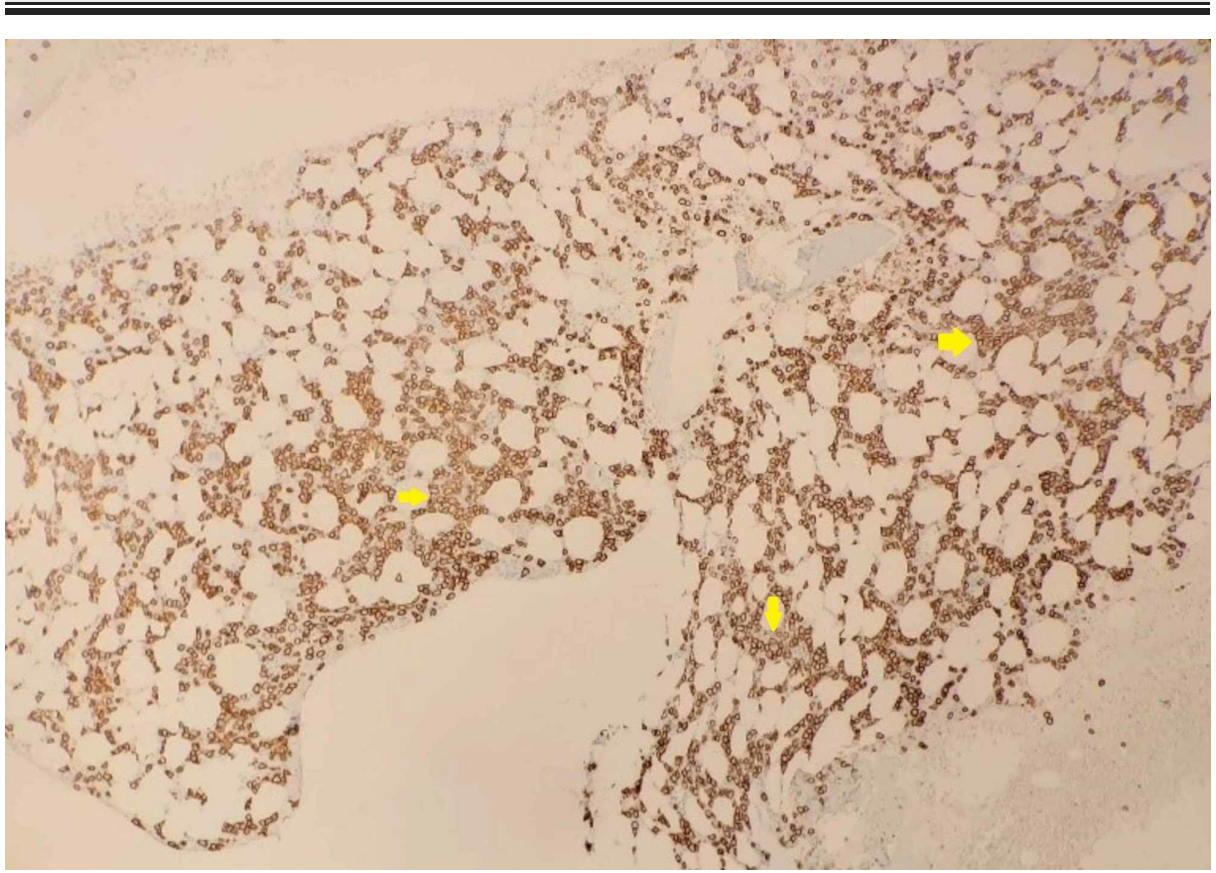

FIGURE 4: Immunohistochemistry with Anti-CD138 Stain of Bone Marrow Biopsy

Drainage of the pleural cavity collected blood-stained pleural fluid with cytologic analysis showing evidence of malignant plasma cells supporting the diagnosis of myelomatous pleural effusion (MPE) (Figures 5-6). 


\section{Cureus}

Inpatient treatment for multiple myeloma was started with three doses of cyclophosphamide, bortezomib, and dexamethasone (CyBorD); however, rapid reaccumulation of the malignant pleural effusion required a second drainage within one week. Given the aggressive nature of her disease, treatment was switched to a bortezomib, daratumumab, and dexamethasone regimen, which induced a prompt response and resolution of the effusion and near normalization of the light chain ratio within one month. The patient is now able to perform activities of daily living independently while receiving treatment.

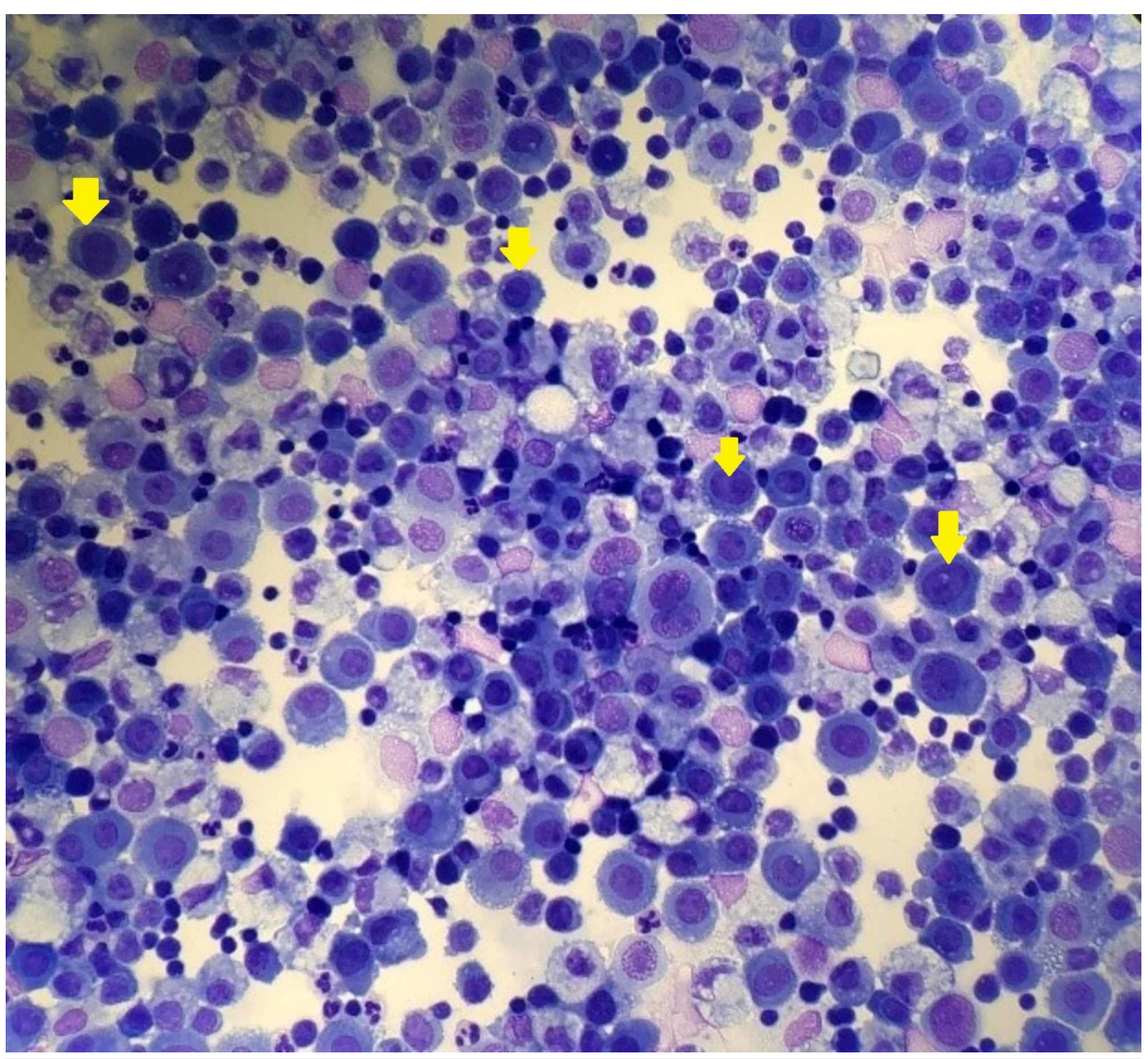

FIGURE 5: Hematoxylin and Eosin Stain of Pleural Fluid Cell Block 


\section{Cureus}

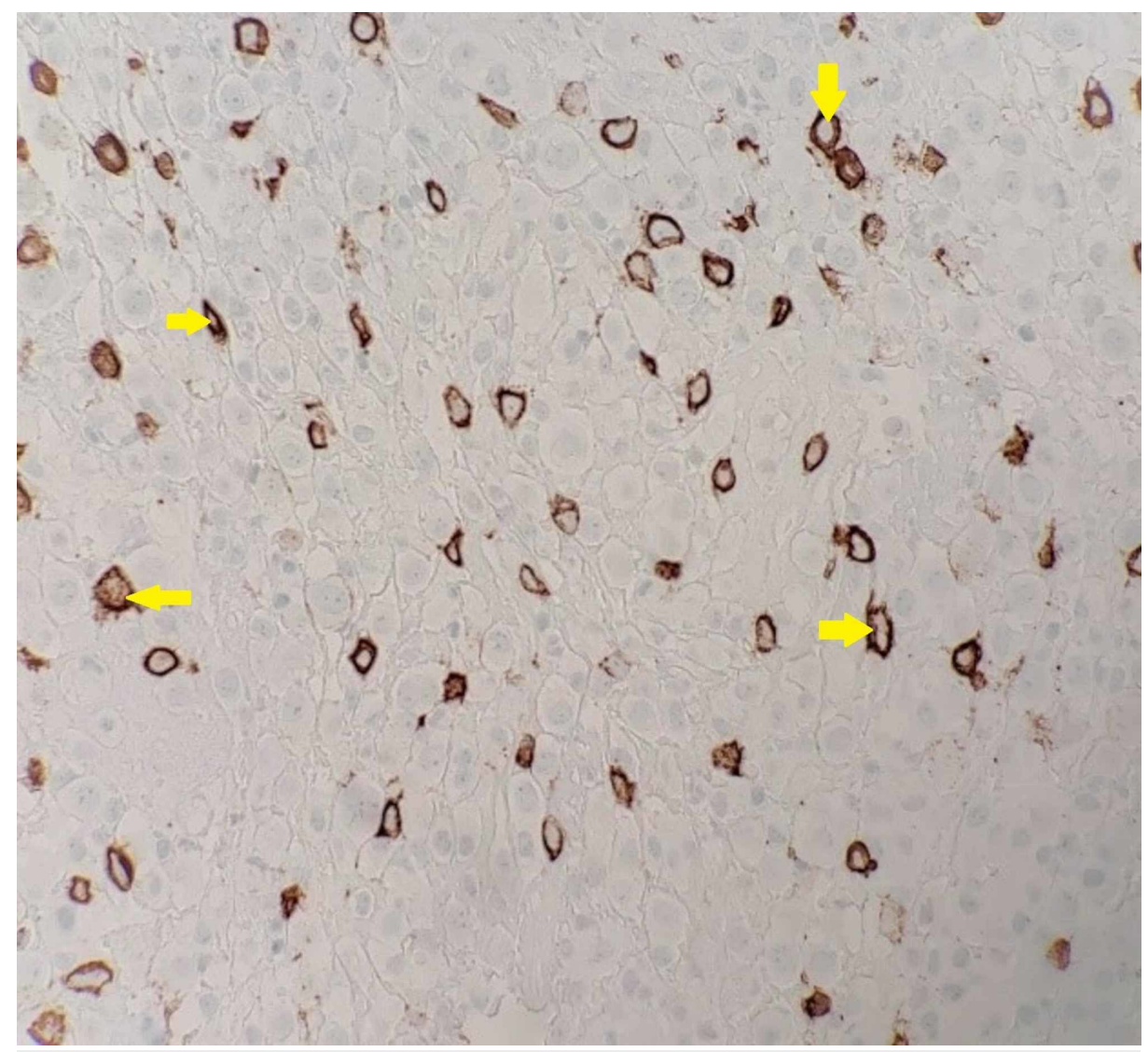

FIGURE 6: Immunohistochemistry with Anti-CD138 Stain of Pleural Fluid

\section{Discussion}

Six percent of patients with MM may present pleural effusion as a clinical symptom, with a plain range of distinct etiologies: pulmonary embolism, lymphatic drainage obstruction, chronic renal failure, and pleural myelomatous involvement; the latter represents less than $1 \%$ of all patients and is usually significant for aggressive disease and unfavorable prognoses, with a median survival time of four months [3-5]. To the best of our knowledge, concomitant pericardial effusion and MPE as initial manifestations of MM have not been reported previously.

The mechanism of disease for MPE is unknown. Local invasion from nearby bone lesions and direct infiltration as in a pleural plasmacytoma are believed to both be possible pathways for the development of this condition, most commonly presenting in later stages of MM [6].

Cytological analysis of the pleural effusion is the most common diagnostic method. A pleural biopsy may be a useful diagnostic test in excluding other etiologies (mesothelioma, extramedullary plasmacytoma) [7]. Pleural effusions in MM predominantly occur in the immunoglobulin A (IgA) subtype, up to $80 \%$ of all reported cases, thus making our case an abnormal presentation of an uncommon complication [8].

No official guideline exists for the management of MPE. Initial therapy should focus on performing a diagnostic and therapeutic thoracocentesis causing an overall respiratory symptomatic improvement. Chemotherapy treatment is usually initiated once a diagnosis has been established with variable reported results. Total regression of the MPE after only one cycle has been reported [9].

We opted for a more aggressive approach to therapy given the rapid recurrence of the MPE after an initial cycle of the CyBorD regimen, as the bortezomib, daratumumab, and dexamethasone regimen has proven to be effective in refractory MM $[10]$.

\section{Conclusions}

Our case demonstrates the importance of considering MPE as a possible initial presentation of MM. The development of further studies and guidelines for the management of this condition could improve the low survival rates in this patient population, especially with the recent approval of agents with high efficacy in the relapsed setting. These patients may be treated similarly as ones with poor cytogenetics given the 
aggressive symptomatic course and short survival. The role of high dose chemotherapy with stem cell rescue is unclear but may be considered for appropriate patients.

\section{Additional Information \\ Disclosures}

Human subjects: Consent was obtained by all participants in this study. Conflicts of interest: In compliance with the ICMJE uniform disclosure form, all authors declare the following: Payment/services info: All authors have declared that no financial support was received from any organization for the submitted work. Financial relationships: All authors have declared that they have no financial relationships at present or within the previous three years with any organizations that might have an interest in the submitted work. Other relationships: All authors have declared that there are no other relationships or activities that could appear to have influenced the submitted work.

\section{References}

1. Rajkumar SV: Multiple myeloma: 2016 update on diagnosis, risk-stratification, and management . Am J Hematol. 2016, 91:719-734. 10.1002/ajh.24402

2. Kamble R, Wilson CS, Fassas A, et al.: Malignant pleural effusion of multiple myeloma: prognostic factors and outcome. Leuk Lymphoma. 2005, 46:1137-1142. 10.1080/10428190500102845

3. Natori K, Izumi H, Nagase D, et al.: IgD myeloma indicated by plasma cells in the peripheral blood and massive pleural effusion. Ann Hematol. 2008, 87:587-589. 10.1007/s00277-008-0444-5

4. Oudart JB, Maquart FX, Semouma O, Lauer M, Arthuis-Demoulin P, Ramont L: Pleural effusion in a patient with multiple myeloma. Clin Chem. 2012, 58:672-674. 10.1373/clinchem.2010.160994

5. Zhang LL, Li YY, Hu CP, Yang HP: Myelomatous pleural effusion as an initial sign of multiple myeloma-a case report and review of literature. J Thorac Dis. 2014, 6:152-159. 10.3978/j.issn.2072-1439.2014.06.48

6. Williams G, Kadaria D, Sodhi A: Concurrent myelomatous pleural effusion and extramedullary mediastinal involvement as an initial manifestation of multiple myeloma. Am J Case Rep. 2016, 17:472-475. 10.12659/AJCR.898849

7. Lang K, Lidder S, Aitchison R: Massive pleural effusion due to IgG multiple myeloma . Hematol Rev. 2009, 1:18. 10.4081/hr.2009.e18

8. Rodriguez JN, Pereira A, Martinez JC, Conde J, Pujol E: Pleural effusion in multiple myeloma . Chest. 1994, 105:622-624. 10.1378/chest.105.2.622

9. Uskül BT, Türker H, Emre Turan F, Unal Bayraktar O, Melikoğlu A, Tahaoğlu C, Oz B: Pleural effusion as the first sign of multiple myeloma. Tuberk Toraks. 2008, 56:439-442.

10. Palumbo A, Chanan-Khan A, Weisel K, et al.: Daratumumab, bortezomib, and dexamethasone for multiple myeloma. New Eng J Med. 2016, 375:754-766. 10.1056/NEJMoa1606038 